\title{
Employees' Performance Based on Leadership Styles and Big-Five Personality Mediated by Integrity
}

\section{Made Putrawan}

\begin{abstract}
This research was aimed at finding out the information about the mediated role of integrity (IN) between leadership styles (LS) and big-five personality (BFP) with employees' performance (CB). A causal survey method used by involving 231 employees of private university in Jakarta. There were four instruments developed for measuring $C B(32$ items, rel. 0.894), LS (27 items, reliability was 0.951), BFP (28 items, rel. 0.953 ), and IN (26 items, rel. 0.943). Data analyzed by path analysis. Findings revealed, it was significant influence of leadership styles, big-five environmental personality (BFP), and integrity on employees' performance. Employees' integrity was good and strong mediated factor. Leadership and personality were two factors which is undoubted its effect on employees' $C B$, especially dealing with transformational leadership styles and personality as well. Moreover, integrity dimension of honesty and consistency needed to be taken into account when employees performance would be changed. This result implied that those variables are strongly support the organizational behavior model in achieving organizational goal.
\end{abstract}

Key words: big-five personality, citizenship behavior, path analysis

\section{INTRODUCTION}

In most countries, there are many problems should be tried to find out solutions by avoiding create a new problem. Some are poverty, illiteracy, environmental degradation, political instability, tolerance, consumerism, morale development, character building, digitalization, tourism, etc., that is why development process is inevitable. It should be chosen based on the priorities when resources are scare and limiting one. Development in tourism in term of hotel should put in advanced concurrent to economic development. Talking about tourism related to the hotel. As a country where human resources is a problem, recruitment of hotel' employee process could not be neglected. In htis case, hurman resource managment in term of human capital management should be paid a lot of attention.

Human resource managemnt has a vital role in changing people way of life and should be met with human basic needs, particularly at work place. It is enable for her/him to adapt with the environment. Knowledge, attitudes and skills found out from the human capital management, more specifically from training and educational process. In this case, leaders have the idealized influence on their followers to be more positive in their behavior. The role of leaders are not just merely transferring their knowledge or experiences to staffs, but motivate, inspiring, directing, guiding, consulting, stimulating them as well. These leaders activities at the work place called consideration and initiating structure which would affect emplloyees performance/behavior (Woods, 2013 and Kreitner \& Kinicki, 2011). ${ }^{1,2}$

How does it work? It depends on how well leaders perform and to what extent their integrity as a professional leader. Employees performance in term of their citizenship behavior, to borrow Woods $(2013)^{1}$ term, would have an important and as a determinant factor related to employees' change. Employees' integrity which is part of trust dimension and influenced by honesty, consistency, and trustworthiness, would have never been evaluated, particularly, its strengths or weaknesses.

Therefore, in this research, research problems was whether theoretical model about the relationship of employees performance (CB) with leadership and big-five personality mediated by employees integrity confirmed by empirical findings model.

\section{LITERATURE REVIEWS}

Before solving those problems, it should be made clear what actually meant by citizenship behavior (CB) is part of job performance, leadership, personality and integrity which is also part of trust (Mullin, et.al. (2010). ${ }^{3}$ Woods (2013)) ${ }^{1}$ defined job performance as the set of employee behaviors which characterized by a set of values in term of positive contribution given by employees in achieving organizational goals,

Hoy \& Miskel (2013), ${ }^{4}$ on the other occasion, stated that "performance is one of the wise behavior which set as a contributor in goal achievement. Products of performance indicated by achievement, job satisfaction, absenteeism, and performance quality which will affect turn-over rate

Organizational citizenship behavior (OCB), according to Ivancevich, et.al. (2014) $)^{5}$ stated that "it is kind of volunteer behavior which positively contribute to the accomplishment of organization goals." As an addition to those definition, Newstrom, et.al. $(2015)^{6}$ defined that organizational citizenship behaviors as a wise work or job which completely influenced by employees willingness to go beyond the target of tasks." Gibson, et.al. (2012) ${ }^{7}$ described that "OCB is indicated by sportsmanship, courtesy and civics of among employees that positively influence the 
organization's goals achievement".

Organizational Citizenship Behavior (OCB) has been measured by developing an instrument developed by Podsakoff et al. (1990). ${ }^{8}$ it was consisted of five dimensions of OCB identified by Organ (1990), ${ }^{9}$ such as conscientiousness, sportsmanship, courtesy, civic virtue, and altruistic. Only 10 are being used to measure OCB which measuring employees' behaviors towards fellow workers and organization (Ryan, 2002). ${ }^{10}$

Ebru Oguz $(2010)^{11}$ research findings showed that a reletionaship found significantly between leader behavior and performance by involving 204 sample. Podsakoff, et.al., $(2000)^{12}$ stated and consistent to prior research which provided a positive relationship between leadership styles and OCB. Bass \& Riggio (2006), ${ }^{13}$ described that transformational leaders motivate subordinates to achieve successful performance (OCB) based on its meaning and understanding. As quoted by Oguz (2010, p. 1189, based on Shamir, et.al. (1993), ${ }^{11}$ stated that transformational leadership would provide meaning which could drive followers to be more respective in achieving goals due to its stimulating followers' CB (Podsakoff, et.al., 1990). ${ }^{8}$

Related to integrity Lapidot, et.al. (2007) ${ }^{14}$ defined that it is a moral-ethical diemnsions which direct employees works and support the primary missions of the organization, by considering leader to have integrity, leader characteristics contributing to perceptions of trustworthiness as well due to integrity indicated by this trustworthiness. Since a little support to the statement given in explaining leadership by integrity and rare of research discussed about the relationship between integrity with OCB (Organ, 1990) ${ }^{15}$ based on leadership, therefore, this paper will be a compulsory for other relevant findings.

Cho and Ringquist (2010) ${ }^{16}$ found a relationship between integrity and employees CB. Hence in the present study, integrity level of the individual is expected to have some effect on CB. Hooijberg, et.al. (2010) ${ }^{17}$ examined that a relationship among honesty and integrity which integrity has an influence on leader behavior. Research findings found by Meltem Akin Ko $(2015)^{18}$ described that an association found significantly among teachers' leadership and academic press with job performance.

Regression analyses show transformational leadership affected and predicted strongly on teachers' job satisfaction, organizational commitment, and organizational citizenship behavior (Nguni, Sleegers, Denessen, 2006). ${ }^{19}$ used empowerment as mediated factor between teachers' leadership and teachers' OCB. A research findings have been reported which found that leadership influenced significantly on employees satisfaction, justice, organizational commitment, trust, organizational culture and climate, and also affected on performance $[r=.35]$.

In addition to those findings, Ahmet AVCI (2016) ${ }^{21}$ found that teachers' perceptions meant regarding the transformational and transactional of principals' leadership and the organizational citizenship behavior means, were high. Transformational leadership positively affects organizational citizenship more than transactional leadership. However, evidence showed that the positive relationship between behavior integrity and OCB. The
Bogler \& Somech (2005, in Colgatay \& Karadag, 2016) ${ }^{20}$

research results revealed that integrity has a relationship with followers' performance that was strongly intervened by leader effectiveness (Zhang, Bai, Wang, 2014). ${ }^{22}$ Moreover, the research focuses on the mediating effect of trusting (integrity) between the employee's perception of leader's ability and performance (Jin, Hahm \& Park, 2016). ${ }^{23}$ According to Applebaum (2004) ${ }^{24}$ and Bolino, et.al. (2002), "trust as the belief in organization's integrity," trust as an antecedent, rather than a consequence of OCB.

On the other research findings showed that job attitudes affected on citizenship behavior (OCB) and also on personality. It is assumed that personality would explain the correlation among job attitudes and employees' performance. "A stronger of conscientiousness, one of the Big Five factors, indicated a different profile of personality facets derived from different factors of the Big Five" (Organ, 1994). ${ }^{26}$

Moreover, according to Mullins, et. al. (2010), ${ }^{3}$ personality is a human characteristic or traits as a results of his interaction with the environment which will reflected on his behavior and come up with individual differences in any organization. Those traits relevant to his/her parents based on heredity viewed and will be influenced by his surrounding where he lives (Kreitner, Robert \& Angelo Kinicki (2011). ${ }^{2}$

\section{RESEARCH METHODOLOGY}

This research objective was to get the information about the mediated affect of integrity in influencing directly emnployees' performance as mediator based on the effect of leadership and big-five personality. A causal survey used by selecting 231 of automotive companies employees in Jakarta. There were four instrument which measured employees' perfomance or citizenship behavior (CB) with reliability 0.894 (32 items), leadership (0.951, 27 items), big-five personality $(0.952,28$ items $)$ and integrity $(0.943$ 26 items). Data analyzed by path analysis.

\section{RESULTS AND DISCUSSION}

Considering statistical computation results by applying SPSS, found that integrity was directly and significantly affect employees' performance (CB) with phi-coefficient was 0.555. Integrity which consists of three main dimensions, honesty, consistence, and trustworthness, proved to have high contribution in affecting employees' CB. Employees CB variation should be viewed logically from those dimension if a company need to be improved in getting a better profit which is inevitable factor in any programs to achieve companies goals.

This result also supported by Palanski \& Yammarino $(2011)^{27}$ which found that there is an impact of followers behavioral integrity on followers performance based on leadership derived from three studies. Moreover, there is relationship between authentic leadership and behavioral integrity with performance found by Marcus, et. al. $(2013)^{28}$ and Palanski \& Yammarino (2011). ${ }^{27}$ 
In term of employees' personality which measured by big-five personality, found affected directly and high significantly on employees' performance (CB) and well mediated by integrity ( see figure below). However, which factors among those five-factors has a significant contribution to employees' $\mathrm{CB}$ is still questionable except research conducted by Westerhoft, et.al. $(2015)^{29}$ which found that extraversion and openness has a relationship with integrity (adults $\mathrm{n}=218$ ) could be considered.

On the other occasion, Marcus, et. al. $(2013)^{28}$ found that a combination test of integrity and big five personality contributed to, in this case counterproductive work behavior, but how if it is related to citizenship behavior, still needed other research to be conducted.

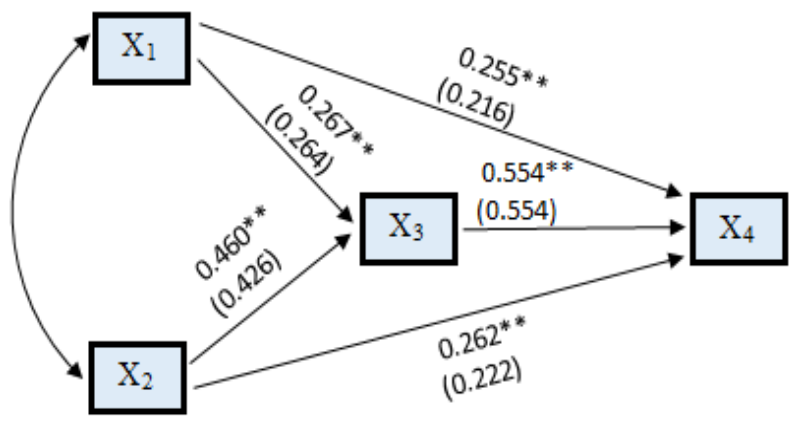

Fig. 1. Empirical Model

$\mathrm{X} 1=$ =Leadership; $\mathrm{X} 2=$ =Personality, $\mathrm{X} 3=$ =Integrity, $\mathrm{X} 4=$ Performance $(\mathrm{CB}) ; * * \mathrm{P}<0.01$

\section{CONCLUSION}

The conclusion of this research findings was directed to employees' performance (CB) improvement which could be empowered by considering how employees perceive style of superordinate leadership, whether transformational direction or reversely by transactional tendency, and characteristic of employees, in term of their personality which influenced by five-factors as well and finally would be well mediated by integrity. Therefore, leadership, personality and integrity could not be neglected when employees' performance or citizenship behavior CB) could be improved and developed by company.

\section{ACKNOWLEDGEMENT}

This research was not sponsored by any institution, fully conducted by our self and helped by Lisa Dwi Ningtyas in preparing and editing this manuscript.

1. Woods, et.al., Organizational Behavior, Pearson, 2013.

2. Kreitner, Robert \& Angelo Kinicki, Organizational Behavior, Irwin: McGraw Hill, 2011.

3. Mullins, Laurie J. Management and Organizational Behavior, London: Prentice Hall, 2010.

4. Hoy, Wayne K. dan Cecil G. Miskel, Educational Administration, theory, research and practice Ninth Edition. New York: McGraw-Hill, 2013.

5. Ivancevich, John M., Robert Konopaske, M.T.Matteson, Organizational Behavior and Management, Irwin: McGraw Hill, 2014.

\section{REFERENCES}

6. Newstrom, J.W., Organization Behavior, New York McGraw Hill, 2015.

7. Gibson, James L. et.al. Organization: Behavior Structure, Process, Boston: McGraw-Hill, 2012.

8. Podsakoff, P. M. et.al., "Transformational leader behaviors and their effect on followers'trust in leader, satisfaction, and OCB," The Leadership Quarterly, vol. 1, no. 2, 1990, pp. 107-142.

9. Organ, Dennis W., "The motivational basis of organizational citizenship behavior," In B. M. Staw \& L. L. Cummings (Eds.), Research in organizational behavior, vol. 12, 1990, pp. 43-72.

10. Ryan, J., "Work Values and Organizational Citizenship Behaviors Values That Work For Employees and Organizations," Journal of Business and Psychology, vol. 17 , no. 1,2002 , pp. $1-16$.

11. Ebru, Ogus, "The relationship between the leadership styles of the school administrator and the OCB of teachers," Procedia Social and Behavioral Sciences, vol. 9, 2010, pp. 1188-1193.

12. Podsakoff, P. M. et.al., "OCB: A critical review of the theoretical and empirical literature and suggestion for future research," Journal of Management, vol. 26, no. 3, 2000, pp. 513-563.

13. Bass, B. and R. E. Riggio, Transformational Leadership New Jersey: Lawrence Erlbaum Associates, 2006.

14. Lapidot, Y., R. Kark, and B. Shamir, "The impact of situational vulnerability on the development and erosion of followers' trust in their leader", Leadership Quarterly, vol. 18 , no. 1, 2007, pp. 16-34.

15. Organ, Dennis W. "The motivational basis of organizational citizenship behavior". In B. M. Staw \& L. L. Cummings (Eds.), Research in organizational behavior, vol. 12, 1990, pp. 43-72.

16. Cho, Y. J. and E. J. Ringquist, "Managerial trustworthiness and organizational outcomes", Journal of Public Administration Research and Theory, vol. 21, 2010, p. 5386.

17. Hooijberg, Robert and Nancy Lane Albert Diverse, "Leader effectiveness and integrity: wishful thinking?", International Journal of Organizational Analysis, vol. 18 , no. 1,2010 , pp. $59-75$.

18. Meltem Akin Ko" STERELIOG LU, "The effect of teachers' shared leadership perception on academic optimism and organizational citizenship behavior: a Turkish case," International Journal of Leadership Education, 2015 , http://dx.doi.org/10.1080/13603124.2015.1066868

19. Nguni, Samuel, et.al., "Transformational and Transactional Leadership Effects on Teachers' Job Satisfaction, Organizational Commitment and Organizational Citizenship Behavior in Primary Schools The Tanzanian Case, School Effcetiveness and School Improvement," International Journal of Research, Policy and Practice, vol. 17, no. 2, 2006, pp. 145-177.

20. Çoğalta, Nazim and Engin Karadağ, "The Effect of Educational Leadership on Organizational Variables: A Meta-Analysis Study in the Sample of Turkey," Educational Science: Theory \& Practice, vol. 6, no. 2, 2016, pp.603-646.

21. Ahmet AVCI, "Effect of Leadership Styles of School Principals on Organizational Citizenship Behaviors" Educational Research \& Review, vol. 11, no. 11, 2016 , pp. 1008-1024.

22. Zhang, Gang, Yuntao Bai, Arran Caza, and Lu Wang, "Leader Integrity and Organizational Citizenship Behaviour in China," Management \& Organization 
Review, vol. 10, no. 2, 2014, pp. 299-319.

23. Jin, Xiu, Sang-Woo Hahm and Hyungwoo Park, "The Effect of Employee's Cognition of Leader's Ability, Justice, and Integrity on Organizational Citizenship Behavior: Focusing on the Mediating Effect of Trust in Leader," International Journal of Business Policy and Strategy Management, vol. 3, no. 1, 2016, pp. 33-40, http://dx.doi.org/10.21742/ijbpsm.2016.3.06

24. Appelbaum, A., et.al., "Organizational Citizenship Behavior: a case study of culture, leadership and trust," Management Decision, vol. 42, no. 1, 2004, pp. 13-40.

25. Bolino, M. C. and W. H. Turnley, "Going the Extra Mile: Cultivating and Managing Employee Citizenship Behavior," Academy of Management Executive, vol. 17, no. 3, 2002, pp. 60 - 71 .

26. Organ, Dennis W., "Personality and Organizational Citizenship Behavior," Journal of Management, vol. 20 , no. 2, 1994, pp. 465-478.

27. Palanski, Michael e. and Francis J. Yammarino, "Impact of Behavioral Integrity on Follower Job Performance: A thre-Study Examination,“ The Leaderhsip Quartely, vol. 22, 2011, pp. 765-786.

28. Marcus, Bern, et.al., "A Note on the Invremental Validity of Integrity Test Beyond Standard Personality Inventories for the Criterion of Counterproductive Behavior," Canadian Journal of Administrative Sciences, vol. 30, 2013, pp. 18-25, doi:10.1002/CJAS.125.

29. Westerhoft, Gerben J., et.al., "The Relation of Ego Integrity and Despair to Personality Traits and Mental Health, "Journal of Gerontology, vol. 00, 2015, pp. 1-9. 